\title{
ENSP (European Network for Smoking and Tobacco Prevention). 20 years of Tobacco Control in Europe and its effort to reduce health inequalities
}

\author{
Antonella Cardone, Cornel Radu-Loghin \\ The European Network for Smoking and Tobacco Prevention, Brussels, Belgium
}

ADDRESS FOR CORRESPONDENCE: e-mail: a.cardone@uniterzosettore.it

Smoking is the largest single contributor to socioeconomic inequalities in morbidity and mortality. Within most European populations, smoking prevalence rates differ substantially according to people's educational level, occupational class and socio-economic status. Significant inequalities in the characteristics of tobacco use are now emerging across all EU Member States, especially among youth. Furthermore, as smoking is responsible for half the difference in deaths across socioeconomic groups, tobacco control has a major role to play in reducing health and social inequalities. Socioeconomic determinants play an important role in tobacco use, but also in e-cigarette use, in support for tobacco control policies and to the exposure to Second Hand Smoke.

The European Network for Smoking and Tobacco Prevention's (ENSP), is an international organisation based in Brussels with over 70 members, including organisations, individuals and specialised networks active in tobacco control across Europe and beyond.

ENSP's vision for the future is to eliminate the health inequalities attributable to tobacco among European citizens and reduce their suffering caused by early morbidity and early mortality due to tobacco-related diseases. ENSP believes that children and youth should be able to grow up without being targeted with messages that seek to lure them into a lifetime of addiction. Every person living in Europe should be able to breathe clean air unpolluted by tobacco smoke. This is why ENSP's mission is to develop a strategy for coordinated action among organisations active in tobacco control in Europe by sharing information and experience and through coordinated activities and joint projects. ENSP aims to create greater coherence among smoking prevention activities and to promote comprehensive tobacco control policies at both national and European levels.
ENSP was formally established in 1997 in Brussels, but the idea to set up a network specifically focused on Tobacco Control started much earlier.

The Europe against Cancer Programme $(\mathrm{EaC})$ was initiated by EU Heads of State and Government in 1985. A 'Committee of Cancer Experts' was convened, which proposed a preliminary Action Plan for the years 19871989. The success and learnings from this experience led to a second and more ambitious plan for 1990-1994, based on three clear and separate strands: cancer prevention, early diagnosis and treatment, and quality assurance of treatment services.

Tobacco use was identified as the most significant cause of avoidable cancer, and addressing the tobacco 'problem' became the most significant priority for the prevention strand. This decision had consequences for the Commission Services and for the tobacco industry.

The Commission had no in-house expertise, able to document, quantify, compare and analyse the scale and consequences of tobacco use throughout the Member States; nor to recommend appropriate counter-measures. So, in 1988 a contract was awarded to a Brussels-based group: The European Bureau for Action on Smoking Prevention (BASP). BASP produced quarterly newsletters on tobacco-control developments within the EU, at Member State level and internationally. Under the stimulus provided by the EaC programmme regular meetings began to be held at EU level. These involved existing European networks, such as the Association of European Cancer Leagues (ECL) and the European Heart Network (EHN), and also helped to create new ones - e.g., amongst national anti-tobacco organisations. To reduce tobacco consumption, many different national pilot projects were funded with the aim to identify good practices, which could serve as examples for other 
countries. Funds were provided to projects aimed at building European networks, such as: GLOBALINK (an international electronic network established to exchange information on tobacco control) led by UICC; a European young people's network of "Smoke Busters", European Networks of smokefree cities, smokefree hospitals and smokefree GPs.

In 1994, the political environment of the 'EaC' programme changed. The 'EaC' Programme was integrated into the DG V Unit - 'Implementation of disease-specific programmes and actions'. A head of sector 'Europe against Cancer' and various new officials were appointed, based in the Commission's offices in Luxembourg.

At the time, the tobacco industry was trying to exclude BASP from future European funding - accusing the Commission of funding an organisation designed to lobby (i.e., the Commission) in support of its own work programme ('EaC') and legislative proposals (e.g., to increase the size of health warnings, to ban tobacco advertising, etc.). When BASP's contract ended in 1995, BASP stopped its activities.

The evaluation of the second Action Plan 1990-1994 showed that significant progress had been made, particularly in the field of tobacco control legislation, awareness raising on the European Code against Cancer, development of health education strategies on cancer prevention in schools, development of breast cancer and cervical cancer screening networks, training of health professionals as well as studies related to nutrition and cancer. However, it was pointed out that there was a need to strengthen the collaboration between the European Commission and organisations involved at national or European level in the fight against cancer. At the same time, terms of reference for project funding changed. Projects had to show a real European dimension - i.e., include at least six different countries and demonstrate added value that could underpin effective tobacco control measures throughout the Community.

In order to create consensus on how to organise a better co-ordination, information exchange and co-operation among national organisations, the European Commission organised a consensus conference on network development in Empoli, Italy in 1994.

Participants were national representatives of cancer leagues in the European Union, European Network representatives and representatives of the Cancer Experts Committee.

After strong discussions, the "Vinci Resolution" was adopted laying down two main principles for a future action plan:

- the creation of a pan European structure to promote networking at European level,

- the need to create national anti-tobacco coalitions.

It also called for funding of the initiative by the European Commission.

A working group was established in 1995 to elaborate proposals for a structure and financing of the alliance. Members included: Tom Hudson (Irish Cancer Society),
Prof. Albert Hirsch (French National Coalition against Tobacco), Dr. Göran Boethius (Doctors against Tobacco Sweden), Prof. Friedrich Wiebel (German Medical Action Group Smoking or Health), Sibylle Fleitmann (Belgian Cancer Society), Andrew Hayes (UICC/ECL).

It took three years, several unsatisfactory meetings, and the threat of the European Commission to abandon the tobacco control project, before a multinational executive committee was elected from the working group in April 1996 with the mission to make practical proposals to implement the "Vinci Resolution". Based on the experience of previous years, a major challenge was to develop an EU strategy, which took into account different national objectives and priorities, but also political priorities within the European Union.

The executive committee suggested the creation of an independent international non-profit association regrouping all associations working on tobacco control in Europe. The organisation would be jointly funded by the European Commission and by voluntary contributions of the members.

In April 1996, the working group had elaborated common objectives and guidelines for the national coalitions against tobacco. They were proposed to and adopted by the assembly of national representatives of the coalitions. The alliance was created and named "European Network for Smoking Prevention". Eventually a new call for tender was agreed and announced. This included a commitment to networking and providing an information service, but specifically excluded any advocacy activity. Various voluntary sector organisations, including ECL and the Belgian Cancer Society, helped to draft the successful bid.

In October 1996, at the Smokefree Europe: Conference on Tobacco or Health, held in Helsinki, Finland, Commissioner Padraig Flynn, in charge of Employment and Social Affairs, officially launched the European Network for Smoking Prevention.

The collaboration with the European Commission was strong and favoured a win-win situation. ENSP had the opportunity to set up collaborations at national level not only amongst cancer societies and anti-tobacco associations but with all health-related organisations that could join the fight for effective tobacco control policy. National coalitions were created and motivated to adopt a common strategy in their country and at European level. European tobacco control priorities were agreed within the network, which guided the development of joint project applications and ensured that real European 'added value' flowed from all tobacco control project funding.

Since 1997, when ENSP was formally established under Belgian law, ENSP has changed the face of Tobacco Control at national, European and international level. Major successes include:

- The creation and support provided to a number of critical networks to the development of Tobacco Control in Europe and beyond, such as GLOBALINK, the Euro- 
pean Network of Smokefree Hospitals, INWAT (International Network of Women against Tobacco) Europe and the European Network of Quitlines, among others.

- The support to the development of a European directive banning smoking at the work place and promotion and implementation of national legislation banning smoking in public places.

- The EU directive proposal regarding the manufacture, presentation and sale of tobacco products (COM [1999] 594 final). ENSP had actively participated in European policy building by co-ordinating activities and developing common strategies in support of the EU Directive and these activities were instrumental to the successful adoption of the proposal by the Health Council and European Parliament in May 2001.

- The transposition into national legislation of the European advertising directive (98/43/EC) and its implementation, which was particularly painful, as it was annulled by the judgement of the European Court of Justice on 5 October 2000. To a better co-ordinated approach, ENSP, together with the European Respiratory Society and the European Heart Network, formed the consortium ASPECT and published a joint report Tobacco Health in the European Union - Past, Present and Future.

- The contribution to the establishment of the World Health Organisation Framework Convention on Tobacco Control (WHO FCTC) since the 1999, when the need to control the spread of tobacco epidemic was formally recognised by the 191 members of the World Health Assembly (WHA) and it was decided to initiate the first international treaty on health. It took 4 years of hard work and negotiations and in 2003 the WHA unanimously adopted the WHO FCTC. Since then ENSP has been producing regular shadow reports on its implementation in Europe.

- Tracking and follow-up of tobacco subsidies, particularly the development and use of the Tobacco Fund. ENSP campaigned with other networks, such as the European Cancer Leagues, the European Heart Network, the European Respiratory Society and achieved that tobacco subsidies would be phased out completely by 2010 .

- Contributed to the EU Commission draft legislative proposal published on 16 July 2008 for a Directive amending Directives 92/79/EEC, 92/80/EEC and 95/59/ $\mathrm{EC}$ on the structure and rates of excise duty applied on manufactured tobacco.

- Following the submission of an application in May 2010, the WHO FCTC Conference of the Parties (COP) awarded ENSP the observer status in time for COP4. This step was significant in two ways: ENSP members could be admitted to COPs as part of the ENSP delegation and it strengthened the European presence at COPs.

- ENSP received in 2011 the World No Tobacco Day WHO Award directly from the hands of the WHO Regional Director for Europe Zsuzsanna Jakab.
- Strong support to the revision process of the Tobacco Products Directive 2001/37/EC, which led into the new Tobacco Products Directive (2014/40/EU) voted by the European Parliament in February 2014. It was expected to improve the functioning of the internal market for tobacco and related products, while ensuring a high level of health protection for European citizens. The new Directive entered into force on 19/05/2014.

- In compliance with the implementation of FCTC Article 14, ENSP developed the first European Smoking Cessation Guidelines (ESCG) with the support of an Editorial Board in 2011. The ESCG together with the Quality Standards in tobacco dependence treatment were launched at the European Parliament in Brussels on 3 October at an event hosted by the MEP Oana Antonescu. Since then the guidelines have been constantly updated and translated in several languages, including Turkish, Russian, Greek, Armenian, Georgian and Romanian. Now they are the most up to dated Smoking Cessation Guidelines globally.

- The ENSP scientific online journal "Tobacco Prevention and Cessation", launched in 2015, which received over 109 submissions in 2016 with 34 articles and 45 abstracts published. The journal's publications were downloaded of a total number of 8.470 times. The journal is a unique tool to share scientific information, latest evidence and advocacy materials.

Particularly relevant is the work ENSP did to support the development of Tobacco Control and capacity building in Eastern Europe.

Thanks to ENSP in June 1998 the first national tobacco control coalition of the whole Eastern Europe was established in the Czech Republic. The coalition counted 29 members, mostly governmental and non-governmental organisations.

In May 2003, the Polish coalition joined ENSP and it was agreed that the Polish coalition would host the ENSP Network Meeting and General Assembly in Cracow in May 2004. It was the first EU Accession Country, at the time, to host such an event. This was very important for Poland, as it gave them visibility and credibility in the country and in Europe. In 2004 Prof. Witold Zatoński from the Health Promotion Foundation in Poland joined the Board of ENSP for two years. In 2015 Krzysztof Przewoźniak, Foundation "Smart Health - Health in 3D", Poland was elected new member of the Board for the next three years, until 2018.

As Cornel Radu Loghin, ENSP Secretary General (2015 to date) stated: "Looking back at the last 20 years, it is almost impossible to talk about tobacco control in Europe without mentioning the involvement of at least one ENSP member. At every level, from international to the very local one, ENSP members have played a vital role to change policies, as well as culture. But the work has always been a concerted effort for a common accomplishment. This is the very essence of a network, an inter- 
connected group that acts in a consistent and coordinated way. Each node adds value, each link adds strength".

\section{DISCLOSURE}

Authors report no conflict of interest.

\section{References}

1. Cardone A. The Network - European Network for Smoking and Tobacco Prevention (1997-2017) - 20 years of Tobacco Control history in Europe. May 2017.

2. Available from: www.ensp.org (accessed: 10 February 2017).

\section{AUTHORS' CONTRIBUTIONS:}

AC collected data. AC, CRL prepared concept and design, wrote the article, critically reviewed and finally approved it. 